\title{
Methods to Assess Costs of Drought Damages and Policies for Drought Mitigation and Adaptation Review and Recommendations
}

\author{
Journal Article \\ Author(s): \\ Logar, Ivana; Bergh, Jeroen C.J.M. van den \\ Publication date: \\ 2013-04 \\ Permanent link: \\ https://doi.org/10.3929/ethz-b-000065137
}

Rights / license:

In Copyright - Non-Commercial Use Permitted

Originally published in:

Water Resources Management 27(6), https://doi.org/10.1007/s11269-012-0119-9 


\title{
Methods to Assess Costs of Drought Damages and Policies for Drought Mitigation and Adaptation: Review and Recommendations
}

\author{
Ivana Logar • Jeroen C. J. M. van den Bergh
}

Received: 23 December 2011 / Accepted: 29 July 2012 /

Published online: 9 August 2012

(C) Springer Science+Business Media B.V. 2012

\begin{abstract}
This article examines available methods for assessing all types of drought costs, including both damage costs and costs arising from adopting policy measures to encourage mitigation of, and adaptation to, droughts. It first discusses damage costs, distinguishing between direct, indirect and non-market costs. Then it examines the suitability of existing methods for estimating drought costs in different economic sectors, their underlying theoretical assumptions, complementarity between different methods, and conditions relevant for their application. The latter include precision, ability to deal with future climate change risks, data needs and availability, and required financial and human resources. The article further considers potential policies for drought mitigation and adaptation and different cost types associated with them. It ends with providing recommendations for good practices regarding the use of methods as well as drought mitigation and adaptation policies.
\end{abstract}

I. Logar · J. C. J. M. van den Bergh

Institute of Environmental Science and Technology, Universitat Autònoma de Barcelona, Edifici Cn - Campus UAB, 08193 Bellaterra, Spain

J. C. J. M. van den Bergh

e-mail: jeroen.bergh@uab.es

I. Logar $(\bowtie)$

Swiss Federal Institute of Aquatic Science and Technology (EAWAG), Überlandstrasse 133, 8600 Dübendorf, Switzerland

e-mail: ivana.logar@eawag.ch

J. C. J. M. van den Bergh

Department of Economics and Economic History, Universitat Autònoma de Barcelona,

Edifici B - Campus UAB, 08193 Bellaterra, Spain

J. C. J. M. van den Bergh

ICREA, Barcelona, Spain

J. C. J. M. van den Bergh

Faculty of Economics and Business Administration \& Institute for Environmental Studies, VU University Amsterdam, De Boelelaan 1087, 1081 HV Amsterdam, The Netherlands 
Keywords Droughts $\cdot$ Cost assessment $\cdot$ Market and non-market valuation methods $\cdot$ Natural hazards $\cdot$ Extreme events $\cdot$ Climate change

\section{Introduction}

Drought is a natural hazard which causes many economic, social and environmental problems. It is expected that the intensity and frequency of droughts are going to increase in different parts of the world in the future due to climate change. This will certainly raise the importance of estimating the costs of drought damages and drought mitigation and adaptation policies.

Compared to other natural hazards, such as floods or storms, droughts are harder to identify and more complex to measure because of their unique features. First of all, drought is a relative concept because it depends on deviations from a historical record for a specific area. Besides, it generally develops at a much slower pace and lasts longer than other natural hazards (while its duration can vary considerably), making it difficult to identify an onset or an end of a drought. Moreover, droughts usually cause fewer visible infrastructural damages (except for damages from ground subsidence and fires) and have more indirect and diffuse impacts (scattered in space and across activities). This makes identification and cost assessment of drought damages also more complex than in the case of other natural hazards.

Most studies that estimate the costs of droughts focus on a particular economic sector (e.g., agriculture) or type of drought cost (e.g., economic, environmental or social). There are a few comprehensive economic appraisals of drought damages. The European Commission (2007a) estimates the costs of droughts in Europe over the last 30 years to be at least $€ 100$ billion. The European Environmental Agency reported that economic impact from water scarcity and droughts rose to $€ 6.2$ billion per year in recent years (EEA 2010). This represents around $0.05 \%$ of the GDP of the European Union in 2010 (Eurostat 2011). However, this is likely to be an underestimation since the drought which occurred in Central and Western Europe in 2003 alone has caused an estimated economic damage of more than USD \$13 billion (Munich Re 2004). To provide another indication, Martin-Ortega et al. (2012) appraised the total losses of the drought which affected the Spanish region of Catalonia during 2007 and 2008 at $€ 1.6$ billion. This corresponds to $0.48 \%$ of the Catalonian GDP.

Cost assessments of drought damages and drought mitigation and adaptation policies provide crucial information for decision support and policy development in natural hazard management and planning for adaptation to climate change. However, the existing literature on the costs of drought is scarce, fragmented and heterogeneous (Markandya et al. 2010). The European Commission (2007b) has recognized that there is a lack of information about the economic impacts of water scarcity and a need for further and more accurate cost analyses. For this reason, an important amount of resources is being allocated to improving both data and knowledge on the economic impacts of droughts (e.g., several research projects have recently been launched to address this issue). Therefore, it is becoming increasingly important to identify and evaluate different approaches for estimating the costs of droughts, which can be applied to both drought damages and policies for drought mitigation and adaptation. The objective of this paper is to fill in this gap by providing a comprehensive review of the existing methods for assessing the costs of droughts. The review includes a critical judgement of the applicability, potential and limitations of each method in estimating a range of costs arising from drought impacts and implementation of drought mitigation and adaptation measures. 
The remainder of this article is organized as follows. Section 2 reviews the existing methods for assessing different types of drought costs. Section 3 discusses drought mitigation and adaptation policies, their cost types and associated cost assessment methods. Finally, Section 4 provides recommendations and concludes.

\section{Overview of Methods for Drought Cost Assessment}

This section provides an overview of methods for assessing different types of drought costs - direct, indirect and non-market (intangible) costs. It is important to note that there is no standard terminology or categorization of drought costs in the existing literature. Moreover, various proposed cost categories overlap or are ambiguous. Definitions and the classification of drought costs proposed in this paper represent just one way of distinguishing between different types of drought costs.

Direct costs of droughts refer to losses in resource-based sectors like agriculture (e.g., reduced crop and livestock production), losses related to reduced water availability (e.g., water-providing companies, hydroelectric production, water transport), and damages on buildings and infrastructure due to ground subsidence. The last category has received particularly little attention in the literature. A reason may be the lack of data on damage from subsidence. Indeed, the two studies that exist (Dlugolecki 2007; Corti et al. 2009) have been conducted for the countries where insurance against subsidence exists, which is not the case in most of the countries. Indirect costs from droughts occur as a consequence of biophysical impacts on the economy as a whole, that is, through changes in resourcebased activities on the rest of the economy. They hence often occur later than direct costs. These include increased unemployment, changes in prices of food and timber, trade losses, reduced tax revenues, or losses in economic sectors indirectly related to droughts (e.g., food industry). Non-market or intangible costs of drought are costs associated with environmental, health, and social impacts of droughts. Environmental costs of droughts embrace damage to wildlife and fish habitat, animal disease, loss of biodiversity, loss of wetlands, deteriorated water and air quality, reduced quality or loss of recreational sites, and aesthetic impacts. Health costs primarily refer to an increased risk of diseases, malnutrition and famine due to food shortages. Social costs of droughts involve loss of human lives, migration (usually from rural to urban areas), social conflicts, changes in income distribution, and social welfare losses due to restrictions of water supply in households (e.g., prohibition of water use for swimming pools, gardens, or car washing).

Some of the methods for drought cost assessment can estimate only one cost type (e.g., only non-market costs), while others may be applied to assess two or even all three types of drought costs. In addition, some of the methods can assess drought costs only once a drought has occurred (ex post), while others allow cost assessment of both historical and hypothetical droughts (ex post and ex ante, respectively). Table 1 provides an overview of available methods for estimating different types of drought costs along with some of their main characteristics. These include complementarity between different methods, type of drought cost that can be assessed with the method, expected precision of the method, ability to deal with future climate change risks, data needs and availability, and required financial and human resources. Sections 2.1 to 2.11 describe each of the methods in more details. Although the travel cost method could theoretically be used to estimate some of the intangible drought costs, such as reduced quality or loss of a recreational site (e.g., river, lake or wetland), we have not found a study applying this method in the context of drought damage cost estimation. For this reason, this method does not receive a detailed attention in this article. 


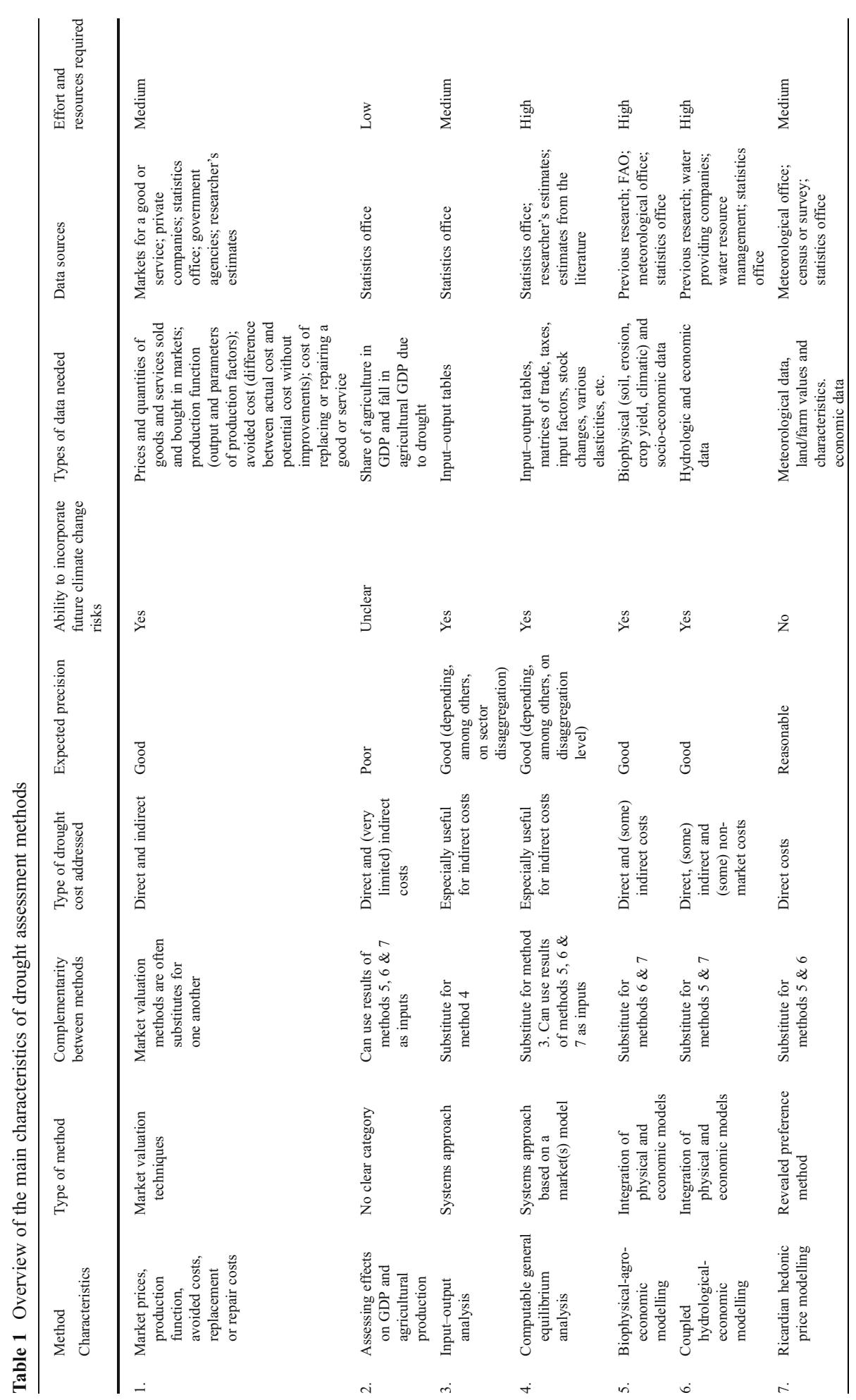




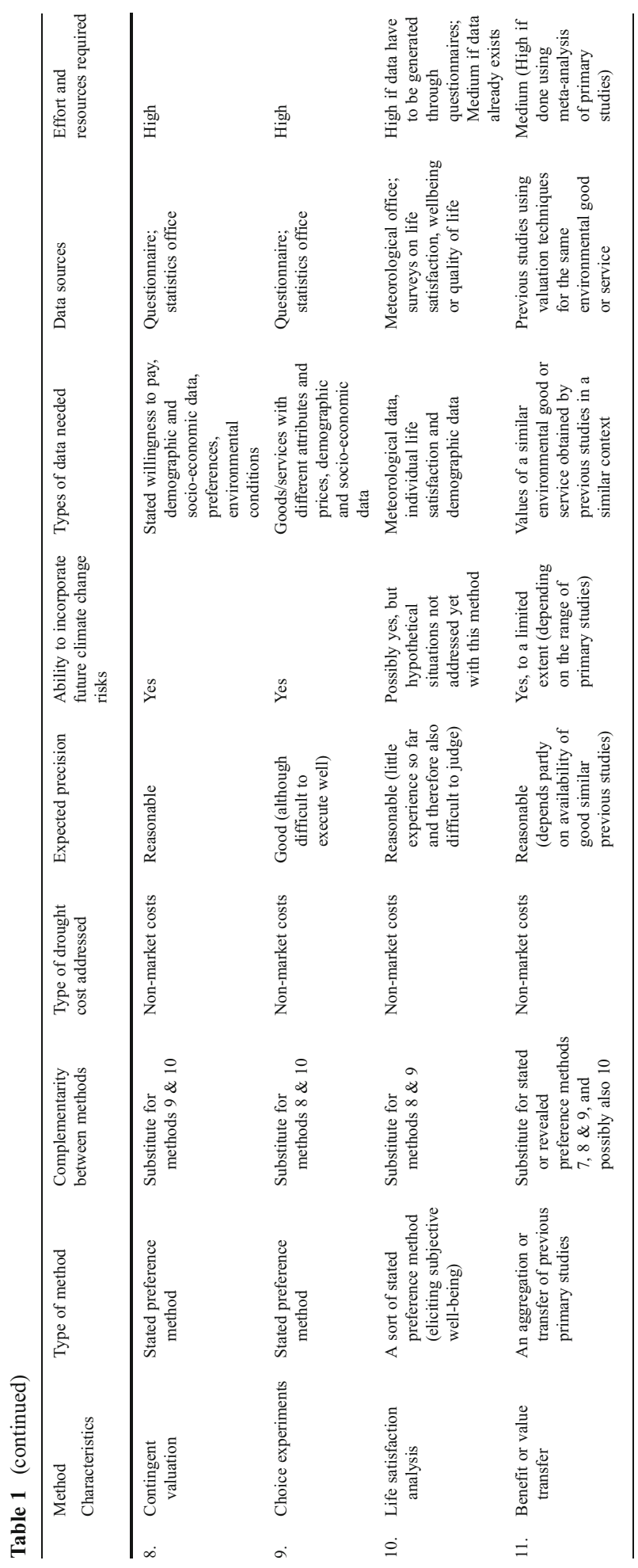




\subsection{Market Valuation Techniques}

Economists prefer to use direct, observable market interactions for placing a monetary value on goods and services whenever possible (NOAA 2011). Methods that are consistent with the market valuation approach include the market price method, production function, avoided cost approach, and replacement or repair cost approach. They are particularly useful for assessing direct costs of drought, but can also be used for estimating certain indirect costs.

The market price method enables estimating the economic value of any product or service that is traded in the market. For example, direct costs of a drought in agriculture can be assessed by observing the quantity of crop lost due to a drought and their market prices. Based on this information, one can estimate consumer and producer surpluses before and after the event. The difference represents the cost of crop production losses due to drought.

A production function specifies the output of a company, an industry or an entire economy based on the combination of inputs, i.e. factors of production. Raw materials and environmental inputs are also used as factors of production in the production of other goods. Assuming that the production function and the parameter values are known, one can then introduce a change in the environmental input (e.g., a deterioration of water quality) and estimate its effect on the output in monetary terms (e.g., a decline in the production of a fishing industry or higher costs of its production).

The avoided cost approach is based on the assessment of expenditures that would be needed to mitigate or compensate negative effects of a change in environmental input. For instance, less water available for agriculture due to a drought can be valued on the basis of expenditures on irrigation.

A replacement or repair cost approach represents another method. It assumes that the costs of replacing or repairing a damaged environmental good or service provide a reasonable estimate of its value. An example is assessing the cost of soil erosion due to a drought by estimating the costs of physically recovering and replacing lost soil, nutrients, and water.

Studies that have used market valuation techniques for assessing losses caused by rationing policies during drought include Woo (1994); Garcia-Valiñas (2006) and Grafton and Ward (2008). In general, they were more frequently applied for estimating the costs/ benefits of drought adaptation measures than for assessing drought damages. Precision of the estimates is expected to be good, although it depends largely on the model parameters and the type of model applied.

\subsection{Assessing Effects on GDP and Agricultural Production}

The approach developed by Benson and Clay (1998) explores the relationship between a drought and the economic performance of a country. More specifically, it compares a change in real Gross Domestic Product (GDP) of the agricultural sector and a change in the total GDP of a country for a year in which a drought occurred with a year prior to drought. The expected precision is poor because factors other than drought that could affect GDP are not taken into account and the underlying assumptions of the method are not very clear. Moreover, this approach does not distinguish between drought effects on different sectors of the economy apart from agriculture.

\subsection{Input-Output Analysis}

Input-output analysis allows examining the effects of a change in a price, output, final demand (including personal consumption, government expenditures, and exports), imports 
or value added elements (labour costs, net taxes, and gross operating surplus) in one or several economic sector(s) on the rest of the economy (Miller and Blair 2009). In the context of droughts, this approach is particularly useful for assessing indirect costs of droughts, i.e. the spillover effect of the losses in agriculture and water-providing sector(s) on other economic sectors. It is a substitute method for the computable general equilibrium analysis, discussed in Section 2.4. The advantage of the input-output model is that it is easier to apply, although it is somewhat less precise due to more restrictive assumptions about substitution of production factors and technological changes. Studies that have assessed indirect costs of droughts with this method include Martin-Ortega et al. (2012) and Pérez y Pérez and Barreiro-Hurlé (2009). Input-output analysis has also been applied for studying the effects of alternative water policies on prices and water consumption in different economic sectors (Velázquez 2006; Llop 2008).

\subsection{Computable General Equilibrium Analysis}

A computable general equilibrium (CGE) model represents one of the most sophisticated economic models, which is used for examining the economy-wide impacts of a change in a policy (e.g., taxation, trading, energy, or agricultural policies), technology, exports, or other exogenous factors. The advantage of both input-output and CGE analyses in comparison with other methods is that they incorporate economy-wide feedbacks in examining different impacts on various economic sectors, thus allowing an assessment of both direct and indirect effects. CGE can thus simulate the effects of a drought on the outputs and employment in different sectors of the economy at the regional or national level. Its drawbacks include heavy data requirements and limited potential to include market imperfections (e.g., it assumes optimal behaviour of consumers and producers, market clearing, and competitive product and factor markets). In a drought context, both CGE and input-output analyses will be more precise if sectors like agriculture, hydro-electricity, water transport and (drinking) water provision are well demarcated and disaggregated. Studies that have applied CGE models with the aim of estimating drought costs include Islam (2003); Horridge et al. (2005); Berrittella et al. (2007); Boyd and Ibarrarán (2009); Pauw et al. (2010), and Wittwer and Griffith (2010).

\subsection{Biophysical-Agroeconomic Modelling}

In biophysical-agroeconomic models crop physiology models are forced with climate scenarios (temperature-precipitation inputs) from hypothetical or historical droughts. They provide biophysical estimates of crop responses to climate events (yield, water, and nutrient use). Therefore, this approach serves to predict how drought conditions affect crop yields and water use. The simulated yield estimates are then incorporated into socio-economic models, usually first for predicting farm-level decisions, which are then aggregated to market levels to predict changes in supply, prices, and economic welfare. Crop yield estimates are expected to be precise, while modelling interactions between crop physiology, climate conditions, and economic factors is too complex to be very precise. Applications of this method are found in Kulshreshtha and Klein (1989); Rosenberg (1993); Holden and Shiferaw (2004), and Fischer et al. (2005).

\subsection{Coupled Hydrological-Economic Modelling}

Coupled hydrologic-economic models serve to analyse the impacts of water allocation and water use by different sectors under alternative policy scenarios. The model usually has three 
components: (1) hydrological factors, (2) economic factors, including the cost of water and profits generated by its use, and (3) institutional factors that affect hydrological and economic components. Hydrological-economic models can be a useful decision-support tool for local, regional, or national authorities and agricultural stakeholders. Translating the results of hydrological model into economic losses provides a relatively good estimate of drought damages, although they might not take into account the marginal value of water availability. Examples of the studies that used such models for assessing drought costs include Booker (1995); Booker et al. (2005), and Ward et al. (2006).

\subsection{Ricardian Hedonic Price Modelling}

Ricardian hedonic price modelling was developed by Easterling and Mendelsohn (2000). It can be considered as a form of hedonic price method, in which the price of a market good is related to its characteristics or the services it provides. The hedonic price method is predominantly applied in environmental economics to analyse variations in housing prices that reflect the value of local environmental services or conditions. Building on the Ricardian model of land value, this method uses the same principle to explain variations in agricultural land prices by variations in climate conditions (temperature and rainfall). Regarding its precision, land value is usually a good indicator of economic welfare because it reflects the present value of a future stream of net revenues. Nevertheless, although a disastrous event usually decreases asset values, sometimes it can increase them because of higher scarcity, making such valuation more complex. In addition, climate is not the only factor that varies across space, so the researcher has to control for variation due to other causes (e.g., soil characteristics or population density). However, not all variables can be precisely measured and controlled for, which can bias the results. This approach can estimate only the costs of droughts related to the agricultural sector.

\subsection{Contingent Valuation}

The contingent valuation method $(\mathrm{CVM})$ is a widely used approach for estimating economic values of environmental goods and services which are not traded in the market and thus have no market price. It can therefore be applied for estimating nonmarket costs of droughts. It is also referred to as a stated preference method because people are asked in a survey to state how much they would be willing to pay for a (change in) specific environmental good or service. An advantage of CVM is that it can address hypothetical changes, e.g., policy changes which are considered but have not yet been implemented. The main disadvantage is that data generated by CVM are hypothetical. Validity of the willingness to pay (WTP) can be tested by comparing the result with those from other valuation studies using other methods, by cross-study analyses (e.g., meta-analyses or benefits transfers), or simulated markets. Such comparisons often show that CVM is likely to slightly overestimate the actual value due to its hypothetical nature. Its validity can also be evaluated by examining consistency of CVM estimates with expectations from economic theory (e.g., a positive relationship between stated WTP and respondent's income). In relation to droughts, CVM has mainly been applied to estimate the value of avoiding water use restrictions or increasing the security of water supply (Bakarat and Chamberlin, Inc. 1994; Howe et al. 1994; Griffin and Mjelde 2000; Koss and Khawaja 2001). In addition, Pattanayak and Kramer (2001a) used it to estimate the value of drought mitigation provided by tropical forest watersheds. 


\subsection{Choice Experiments}

Choice experiments (CE) are another important tool for valuing non-market goods and services. In this method, individuals are asked in a survey to choose among several alternatives in a choice set, where each alternative is described by a number of attributes or characteristics. A price is one of the attributes, which enables estimation of the WTP. CE represent a more recent approach which offers several advantages over CVM. For example, respondents are more familiar with making a choice for a good with a range of characteristics, of which price is one, through daily participation in market transactions, rather than stating a price they would be willing to pay for that good. Moreover, CE enable estimating the value of the individual attributes that make up an environmental good and they avoid some of the biases associated with CVM. They are, however, more difficult to execute than CVM, especially if the number of attributes is large. Like CVM, CE can be used to assess the costs of drought damage, mitigation or adaptation, including foreseen or hypothetical measures. They also suffer from hypothetical bias. Most analyses of CE validity arrive at a positive judgement. Its precision depends mainly on the design of the experiment. Hensher et al. (2005 and 2006) represent the only CE applications related to drought cost estimation.

\subsection{Life Satisfaction Analysis}

In life satisfaction analysis (also referred to as happiness or subjective well-being research) people are asked to assess their current level of happiness. These subjective data are then used jointly with objective data on per capita income, other socio-economic indicators, and environmental conditions, for example, to examine how self-reported well-being varies with prosperity or environmental quality. Econometric modelling is applied to analyse the data. Coefficients from the model are then used to calculate the income-equivalence changes (i.e. losses/benefits) due to a change in self-reported life satisfaction. This is a crucial step that determines the precision of the method and depends primarily on the quality of the model. There is only one study that has applied this approach for estimating non-market costs (social welfare losses) of a drought in Australia by relating life satisfaction with rainfall data (Carroll et al. 2009).

\subsection{Benefit or Value Transfer}

Non-market valuation methods require a survey, which can be costly and time consuming. Hence, the benefit or value transfer method was developed for situations in which the funds and/or time available for data collection are constrained. It is hence particularly useful for estimating the non-market costs of a drought. In this method, a monetary value of an environmental good or service estimated at one site (original study site) is spatially and/or temporally transferred to another site (a new site where information about the monetary value of a similar good or service is needed). The transfer can be done by simply applying a benefit estimate obtained from a similar study to the current case study (benefit estimate transfer), by inserting characteristics of the current case study instead of those from the original study into the econometric model (benefit function transfer), or by constructing a dataset based on a larger number of previous studies and regressing benefit estimates against study characteristics (meta-analysis). Brouwer (2000) provides an overview of the environmental value transfer approach and develops guidelines for its proper application. Martin-Ortega et al. (2012) used this method for estimating the welfare loss caused by deteriorated environmental quality and water supply restrictions for households during a drought in Barcelona. 


\section{Drought Mitigation and Adaptation Policies and Their Cost Assessment}

Drought policy in Europe is still lacking, especially when compared with policies that exist for other types of natural hazards. The most relevant European policy related to droughts is the Water Framework Directive, which highlights the importance of integrated water resource management and engagement of stakeholders. In addition, communications on water scarcity and droughts by the European Commisssion represent important guidelines for developing drought policies and management plans. The third follow-up report (EC 2011) describes measures implemented by member states to combat water scarcity and drought problems and identifies actions to be taken in the future. It also recognizes the need for better planning, such as enhanced integration of water scarcity and droughts in the River Basin Management Plans and in sectoral policies. By the end of 2012, the European Commission plans to publish a policy review for water scarcity and droughts as part of the "Blue Print for Safeguarding European Waters". Another important contribution to drought planning and management is a "Synthesis Report on Management and Policy Options for Conference on Drought", produced by the EU project Xerochore (2009). This report describes the main premises for drought planning and management, identifies research needs and provides guiding principles for developing drought policies and management plans.

Two types of government responses to drought can be distinguished: pre- and post-impact interventions. The former are often referred to as crisis management and the latter as risk management. Post-impact interventions are reactive since measures are implemented after a drought occurs and they focus on treating the symptoms instead of the causes. They include drought relief funds, low-interest loans, subsidies for livestock transportation and feed, provision of food, water transport, and drilling wells for irrigation and public water supplies (Wilhite 2000). This drought management approach has often been criticized as inefficient, ineffective and untimely (Wilhite 1993). It does not foster self-reliance and may even increase vulnerability to droughts.

Pre-impact interventions aimed at mitigating the future impacts of drought, reducing vulnerability, increasing coping capacity, and building resilience are proactive and therefore more recommendable. Examples of such measures include development of an early warning system, preparedness plans, increased water supply, demand reduction (e.g., water conservation programs), crop insurance against droughts, ensuring (the recovery of) good environmental conditions (e.g., wetlands, aquifers), establishment of exchanging centres and assignment contracts for water use rights, and increasing water recycling and reuse. Despite recommendations to shift from crisis to risk management (Wilhite 1993; EU 2006; Xerochore 2009; EC 2010), some of these measures have hardly seen any implementation (e.g., insurance against droughts), while others have much more potential than what has been used so far. For instance, to reduce water demand some of the existing (unsustainable) practices of water use could be reconsidered or stricter standards of water consumption for such activities could be set, particularly in arid areas. Examples include numerous golf courses, swimming pools and aqua parks for tourism purposes in the Mediterranean regions or intensive agriculture based on irrigation (e.g., in Almeria, Spain). Most drought mitigation and adaptation measures are complementary. Therefore, a combination (set) of measures is recommendable since it ensures a better risk distribution and has a synergetic value.

Government officials are often reluctant to implement policies and invest into mitigation because of limited information on the costs and benefits of drought mitigation programmes (Ding et al. 2010). There are very few studies that try to assess the costs of drought prevention, mitigation or adaptation measures. Some of them include Michelsen and Young 
(1993); Woo (1994); Fisher et al. (1995); Pattanayak and Kramer (2001a; 2001b); Morton et al. (2005), and Grafton and Ward (2008).

Most of the costs of drought mitigation and adaptation policies are direct costs which have market values. For example, costs related to monitoring and early warning systems mainly include research and development, engineering, investment and maintenance costs, which are associated with market prices. Hence, the appropriate methods for assessing such costs include market valuation techniques explained in Section 2.1. Construction of new infrastructure for increasing water supply also represents a direct cost that can be valued at market prices. However, it can further have detrimental impacts on social welfare due to the impacts on land fragmentation and aesthetics. Such non-market costs of drought mitigation and adaptation measures can be estimated by using stated preference methods, explained in Sections 2.8 to 2.11. In addition, input-output and CGE analyses (Sections 2.3 and 2.4) can serve to explore the potential effects of alternative water-related policies. Multi-criteria analysis can also be a useful decision-making tool when choosing between different policy options. Rossi et al. (2005) used this method for selecting the preferable mix of drought mitigation measures related to a water supply system in Sicily, Italy.

It would be recommendable to compare the costs of drought mitigation and adaptation policies with the costs of drought prevention and with the costs of potential or historical drought. For example, the US Federal Emergency Management Agency (FEMA) estimated that the country will save at least two dollars on future disaster costs from every dollar spent on mitigation (Natural Hazards Observer 1996). In such analysis special attention should be given to the emergency costs because they may, except temporary measures (e.g., drought relief programmes), include investments in infrastructure that will be used for the next several decades. Therefore, it is important to set a baseline which will determine the share of these costs corresponding to drought damages and the ones that are related to drought mitigation policy. Cost assessment of drought mitigation and adaptation measures should also include transaction costs of enforcing a new policy. This may shed light on the cost-effectiveness of some existing practices. In agriculture it might, for example, prove to be less costly to invest in an irrigation system than to subsidize farmers or provide a drought relief programme. Appropriateness and efficiency of mitigation and adaptation policies may vary depending on the location-specific hydrological, geographical, socio-economic, and institutional conditions. Therefore, it would be useful to develop a conceptual framework for assessing the location-specific costs of measures for coping with climate change (Martin-Ortega 2011).

\section{Recommendations and Conclusions}

This article has examined available methods for assessing the costs of droughts. Drought costs can be classified into drought damage costs and costs of drought mitigation or adaptation policies. In addition, damage costs can be decomposed into direct, indirect and non-market costs.

The most suitable methods for assessing direct costs of droughts include market valuation techniques. They can be applied to any economic sector, are relatively easy to apply and yield rather precise estimates. For assessing indirect costs of droughts, computable general equilibrium (CGE) analysis and input-output analysis are the most complete methods because they take all sectors of the economy into account. However, both of them have several limitations as explained in Sections 2.3 and 2.4. Biophysical-agroeconomic modelling and Ricardian hedonic price modelling focus on the agricultural sector, while coupled hydrological-economic modelling embraces costs which are directly related to water use. These methods are thus able to assess only part of the drought costs. They are particularly useful for estimating direct costs, for which 
they can provide reasonably good estimates. A choice between the methods for estimating nonmarket costs of droughts is less clear. Contingent valuation (CVM) and choice experiments (CE) are alternative methods for eliciting individuals' willingness to pay and are expected to arrive to similar estimates. Recently, CE has become more popular due to several advantages over CVM, although it is also more demanding. Life satisfaction analysis can be regarded as a substitute approach to both CVM and CE. Nevertheless, CVM and CE are often used for calculating hypothetical or future changes, while life satisfaction analysis has only been applied to current or historical situations.

A shift from post-impact interventions towards more effective pre-impact drought mitigation policies is needed. Some of the latter policies have already been widely used in different regions, while others have either not yet been implemented (e.g., insurance) or are able to achieve more ambitious objectives than the ones realized until now (e.g., water demand reduction). Therefore, there is a higher potential capacity for drought mitigation and adaptation in coping with climate change compared to what has been used so far.

It is recommendable to set drought mitigation and adaptation policies for a long term, i.e. 20 or more years in the future. This ensures that the effects of predicted climate change, such as a change in the frequency of droughts, are taken into account. These effects are difficult or even impossible to observe in the short term, so that without long-term planning there may be insufficient incentives to invest in drought prevention, mitigation or adaptation. Moreover, participation of local communities in decision-making processes, policy design and planning may play an important role in mitigating and adapting to droughts. For instance, the social impacts of droughts depend greatly on people's tolerance to, or capacity to live with, less water during a drought period and their willingness and capability to change their habits.

When assessing the costs of drought prevention, mitigation and adaptation, market valuation techniques are the most appropriate choice if market prices are available. Otherwise, nonmarket (stated and revealed preference) valuation techniques can be used. Methods such as input-output, CGE, and multi-criteria analyses can serve as useful decision-making tools when choosing between several alternative policies. It is recommendable that planners conduct a costbenefit analysis in which damage costs of a (potential) drought are compared to the costs of mitigation and adaptation measures. Such an analysis should ideally incorporate drought risk (i.e. the probability of occurrence) under climate change conditions in cost estimates. Given the uncertainty about the risks, more future research could be devoted on finding the most appropriate way to include the drought risk into the cost assessment. In addition, there is a need for comprehensive cost-benefit and cost-effectiveness analyses of various drought mitigation and adaptation policies. Further research is also needed concerning the distribution of drought costs among different economic sectors and social actors.

Acknowledgments This paper is based on a report (Logar and van den Bergh 2011), written in the context of the EU 7th Framework Programme project ConHaz (Costs of Natural Hazards). We thank the partners in this project and the participants of the drought expert workshop "Assessing the Costs of Droughts" (held in February 2011) for valuable comments and suggestions.

\section{References}

Benson C, Clay E (1998) The impact of drought on Sub-Saharan African economies: a preliminary examination. World Bank Technical Paper no. 401. The World Bank, Washington, DC

Berrittella M, Hoekstra YA, Rehdanz K, Roson R, Tol RSJ (2007) The economic impact of restricted water supply: a computable general equilibrium analysis. Water Res 41:1799-1813 
Booker JF (1995) Hydrologic and economic impacts of drought under alternative policy responses. Water Resour Bull 31:889-906

Booker JF, Michelsen AM, Ward FA (2005) Economic impact of alternative policy responses to prolonged and severe drought in the Rio Grande Basin. Water Resour Res 41:W02026. doi:10.1029/2004WR003486

Boyd R, Ibarrarán ME (2009) Extreme climate events and adaptation: an exploratory analysis of drought in Mexico. Environ Dev Econ 14:371-395

Brouwer R (2000) Environmental value transfer: state of the art and future prospects. Ecol Econ 32:137-152

Carroll N, Frijters P, Shields MA (2009) Quantifying the costs of drought: new evidence from life satisfaction data. J Popul Econ 22:445-461

Bakarat and Chamberlin, Inc. (1994) The value of water supply reliability: results of a contingent valuation survey of residential customers. California Urban Water Agencies. www.cuwa.org/ library/TheValueofWaterSupplyReliability.pdf

Corti T, Muccione V, Köllner-Heck P, Bresch D, Seneviratne SI (2009) Simulating past droughts and associated building damages in France. Hydrol Earth Syst Sci 13:1739-1747

Ding Y, Hayes MJ, Widhalm M (2010) Measuring economic impacts of drought: a review and discussion. Papers in Natural Resources, University of Nebraska - Lincoln. http://digitalcommons.unl.edu/cgi/ viewcontent.cgi? article $=1198 \&$ context $=$ natrespapers

Dlugolecki A (2007) The cost of extreme events in 2030. A report for United Nations Framework Convention on Climate Change. http://unfecc.int/files/cooperation_and_support/financial_mechanism/application/ pdf/dlugolecki.pdf

Easterling W, Mendelsohn R (2000) Estimating the economic impacts of drought on agriculture. In Wilhite DA (ed.). Drought: a global assessment, 1: 256-268. London/New York: Routledge

EU Working Group on Water Scarcity and Drought (2006) Water scarcity management in the context of WFD. http://ec.europa.eu/environment/water/quantity/pdf/comm_droughts/8a_1.pdf

European Commission (2007a) Addressing the challenge of water scarcity and droughts in the European Union. Communication from the Commission to the European Parliament and the Council. Brussels: COM (2007), 414. SEC (2007) 993 \& 996

European Commission (2007b) Water scarcity and droughts. In-depth assessment. Second Interim Report. http://ec.europa.eu/environment/water/quantity/pdf/comm_droughts/2nd_int_report.pdf

European Commission (2010) Second follow up report to the communication on water scarcity and droughts in the European Union. Report from the Commission to the European Parliament and the Council. Brussels: COM (2010), 228. SEC (2010) 573

European Commission (2011) Third follow up report to the communication on water scarcity and droughts in the European Union. Report from the Commission to the European Parliament and the Council. Brussels: COM (2011), 133. SEC (2011) 338

European Environmental Agency (2010) Mapping the impacts of natural hazards and technological accidents in Europe. An overview of the last decade. EEA Technical Report No. 12/2010

Eurostat (2011) National accounts - GDP. http://epp.eurostat.ec.europa.eu/

Fischer G, Shah M, Tubiello FN, van Velhuizen H (2005) Socio-economic and climate change impacts on agriculture: an integrated assessment, 1990-2080. Phil Trans Roy Soc Lond B Biol Sci 360:2067-2083

Fisher A, Fullerton D, Hatch N, Reinelt P (1995) Alternatives for managing drought: a comparative cost analysis. J Environ Econ Manag 29:304-320

Garcia-Valiñas MA (2006) Analysing rationing policies: drought and its effects on urban users' welfare (Analysing rationing policies during drought). Appl Econ 38:955-965

Grafton RQ, Ward MB (2008) Prices versus rationing: Marshallian surplus and mandatory water restrictions. Econ Rec 84:S57-S65

Griffin RC, Mjelde JW (2000) Valuing water supply reliability. Am J Agric Econ 82:414-426

Hensher D, Shore N, Train K (2005) Households' willingness to pay for water service attributes. Environ Resour Econ 32:509-531

Hensher D, Shore N, Train K (2006) Water supply security and willingness to pay to avoid drought restrictions. Econ Rec 82:56-66

Holden S, Shiferaw B (2004) Land degradation, drought and food security in a less-favoured area in the Ethiopian highlands: a bio-economic model with market imperfections. Agric Econ 30:31-49

Horridge M, Madden J, Wittwer G (2005) The impact of the 2002-2003 drought on Australia. J Pol Model 27:285-308

Howe CW, Smith MG, Bennett L, Brendecke CM, Flack JE, Hamm RM, Mann R, Rozaklis L, Wunderlich K (1994) The value of water supply reliability in urban water systems. J Environ Econ Manag 26:19-30

Islam N (2003) What does a dry season mean to the Western Australian economy? A CGE investigation. Paper presented to the 47th Annual Conference of the Australian Agricultural and Resource Economics Society, Western Australia, 11 - 14 February, 2003. www.aares.info/files/2003_islam.pdf 
Koss P, Khawaja MS (2001) The value of water supply reliability in California: a contingent valuation study. Water Pol 3:165-174

Kulshreshtha SN, Klein KK (1989) Agricultural drought impact evaluation model: a systems approach. Agric Syst 30:81-96

Llop M (2008) Economic impact of alternative water policy scenarios in the Spanish production system: an input-output analysis. Ecol Econ 68:288-294

Logar I, van den Bergh JCJM (2011) Methods for Assessment of the Costs of Droughts. ConHaz WP5 report. http://conhaz.org/CONHAZ\%20REPORT\%20WP05_1_FINAL.pdf

Markandya A, Mysiak J, Palatnik, Brail M, Balzarolo D, Martin-Ortega J (2010) Economic and social impacts of drought and demand side options - state of the art review. Xerochore project background document. www.feem-project.net/xerochore/

Martin-Ortega J (2011) The costs of adaptation to climate change in freshwater systems. Economía Agraria y Resursos Naturales 11:5-28

Martin-Ortega J, González-Eguino M, Markandya A (2012) The costs of drought: the 2007/2008 case of Barcelona. Water Pol 14:539-560

Michelsen MA, Young RA (1993) Optioning agricultural water rights for urban water supplies during drought. Am J Agric Econ 75:1010-1020

Miller RE, Blair PD (2009) Input-output analysis: foundations and extensions. Cambridge University Press, Cambridge

Morton J, Barton D, Collinson C, Heath B (2005) Comparing drought mitigation interventions in the pastoral livestock sector. Natural Resources Institute report. NRI, Greenwich

Munich Re (2004) Annual review: natural catastrophes 2003. Munich Re, Munich

National Oceanic and Atmospheric Administration, Coastal Services Center (2011) Restoration economics. Environmental valuation: principles, techniques, and applications. www.csc.noaa.gov/coastal/economics/ envvaluation.htm

Observer NH (1996) Witt announces FEMA mitigation plan, Natural Hazards Observer, 20: 10. Natural Hazards Information and Applications Center, University of Colorado, Boulder, Colorado

Pattanayak SK, Kramer RA (2001a) Pricing ecological services: willingness to pay for drought mitigation from watershed protection in eastern Indonesia. Water Resour Res 37:771-778

Pattanayak SK, Kramer RA (2001b) Worth of watersheds: a producer surplus approach for valuing drought mitigation in Eastern Indonesia. Environ Dev Econ 6:123-146

Pauw K, Thurlow J, van Seventer D (2010) Droughts and floods in Malawi: assessing the economywide effects. IFPRI Discussion paper 00962. Washington, DC: International Food Policy Research Institute. www.preventionweb.net/files/13792_ifpridp009621.pdf

Pérez y Pérez L, Barreiro-Hurlé J (2009) Assessing the socio-economic impacts of drought in the Ebro River Basin. Span J Agric Res 7:269-280

Rosenberg NJ (1993) A methodology called 'mink' for study of climate change impacts and responses on the regional scale: an introductory editorial. Clim Chang 24:1-6

Rossi G, Cancelliere A, Giuliano G (2005) Case study: multicriteria assessment of drought mitigation measures. J Water Resour Plann Manag 131:449-458

Velázquez E (2006) An input-output model of water consumption: analyzing intersectoral water relationships in Andalusia. Ecol Econ 56:226-240

Ward FA, Booker JF, Michelsen AM (2006) Integrated economic, hydrologic, and institutional analysis of policy responses to mitigate drought impacts in Rio Grande Basin. J Water Resour Plann Manag 132:488-502

Wilhite DA (ed) (1993) Drought assessment, management, and planning: theory and case studies. Kluwer Academic Press, Boston, MA

Wilhite DA (2000) Preparing for drought: a methodology. In Wilhite DA (ed.). Drought: a global assessment, 2: 89-104. London/New York: Routledge

Wittwer G, Griffith M (2010) Closing the factory doors until better times: CGE modeling of drought using a theory of excess capacity. Paper presented at the GTAP 13th annual conference, Penang, Malaysia, June 9-11, 2010. www.gtap.agecon.purdue.edu/resources/download/5019.pdf

Woo C (1994) Managing water supply shortage: interruption versus pricing. J Public Econ 54:145-160

Xerochore (2009) Synthesis report on management and policy options for conference on drought. Background document II (D. 5.1) of the Xerochore project. www.feem-project.net/xerochore/files/D5.1.pdf 